\title{
Knowledge about Danger Signs and Symptoms of Pregnant Women Attending Antenatal Care Centers in Baghdad City.
}

\author{
*Anaam Abdulkareem Abas ${ }^{1}$, Ass.Prof. Dr.Ezedeen Fakhredeen ${ }^{2}$ \\ ${ }^{1}$ (Professor, Maternal and Neonatal Nursing Department, College of Nursing, University of Baghdad) \\ ${ }_{2}^{2}$ (Maternal and Neonatal Nursing Department, College of Nursing, University of Baghdad) \\ Corresponding Author: Anaam Abdulkareem Abas
}

\begin{abstract}
Pregnancy complications are the main cause of maternal mortality in Iraq. Every pregnant woman is at risk of pregnancy related complications.Knowing the signs and symptoms of pregnancy complications and recognizing them is the first step to taking a health care for the pregnant woman in appropriate time.

Objective: To assess the knowledge of pregnant women about danger signs and symptoms during pregnancy and find out the association between pregnant women's knowledge and their some study variables.

Methods: A cross sectional study was conducted between $12^{\text {th }}$ September 2016 to $4^{\text {th }}$ July 2017 at antenatal care centers in Baghdad city. Questionnaire was used as a tool of data collection to fulfill with objectives of the study data was collected through interviewer administered questionnaire from (500) pregnant women. Data are analyzed through the use of SPSS version 21.

Results: Only $6.6 \%$ of the respondents had unacceptable knowledge about danger signs in pregnancy while 93.4\% of them have good knowledge. There was a statistical significant relationships between women's knowledge and socio demographic variables.

Conclusion: This study shown majority of study sample at low knowledge about danger signs andsymptoms.

Recommendation: Raise women's awareness along with the expansion of pregnant care services which may be important strategies to increase the protection of pregnant women from complications of pregnancy.
\end{abstract}

Keywords: Antenatal care centers, Danger signs and symptoms, Knowledge.

Date of Submission: 07-07-2017

Date of acceptance: 17-07-2017

\section{Introduction}

Women die from a wide range of complications in pregnancy, childbirth or after delivery. These life threatening complications are treatable, and thus most of these deaths are avoidable if women with the complications are able to identify and seek timely and appropriate emergency obstetrical care ${ }^{(1)}$ Danger signs in pregnancy are those signs that a pregnant woman will see, or those symptoms that she will feel which refers to that something wrong ${ }^{(2)}$ Health care providers to basis out complications and initiate treatment immediately, the most common danger signs and symptoms during pregnancy that can augment the risk of maternal mortality are: vaginal bleeding, high fever, severe and persistent vomiting in pregnancy period, abdominal pain, severe headaches, absence of fetal movements, severe Fatigue, and gush of fluid from vagina, etc. ${ }^{(3)}$ Pregnant Women's knowledge of the possibility of obstetric danger signs is expected to impact their decisions regarding when to decide to seek medical care. ${ }^{(4)}$

\section{Methods}

A cross sectional study was conducted among pregnant women attending antenatal care centers to assess their knowledge about danger signs and symptoms during pregnancy.The study was performed between $12^{\text {th }}$ September 2016 to $4^{\text {th }}$ July 2017 at antenatal care centers in Baghdad city. Non probability (purposive sample) used to collect the data from (500) pregnant women who attained antenatal care centers in Baghdad City. A questionnaire constructed about knowledge concerning about danger signs and symptoms during pregnancy assessment tool were designed and prepared by the researchers. A pilot study conducted in order to determine the reliability of the questionnaire in a sample of (20) women who excluded from the study sample $(\mathrm{R}=0.96)$. Content validity was determined through a panel of (12) experts their experience mean and SD was 32.5 - 4.7. The data was collected after obtaining the agreement from women to participant in this study. The study instrument was consisted of four main parts which include: Socio demographic characteristics, reproductive variable, and Pregnant Women's knowledge about danger signs and symptoms assessment tool consisted of (42) items. Data are analyzed through the use of SPSS (Statistical Process for Social Sciences) version21. 


\section{Results}

Table (1): Pregnant Women's Socio- Demographic Characteristics $(\mathrm{n}=500)$.

\begin{tabular}{|c|c|c|c|}
\hline Items & & No. & $\%$ \\
\hline \multicolumn{4}{|l|}{ Demographic variables } \\
\hline $15-24$ & & 220 & 44.0 \\
\hline $25-34$ & & 215 & 43.0 \\
\hline $35-45$ & & 65 & 13.0 \\
\hline$x^{-} \pm \mathrm{SD}=25.63 \pm 6.167 \quad$ Min. $=16$ & Max. $=41$ & \multicolumn{2}{|c|}{ Range $=25$} \\
\hline \multicolumn{4}{|l|}{ Level of educational for study sample } \\
\hline No read and write & & 107 & 21.4 \\
\hline Read \&Write & & 64 & 12.8 \\
\hline Primary School graduate & & 102 & 20.4 \\
\hline Intermediate school graduate & & 89 & 17.8 \\
\hline Secondary school graduates & & 48 & 9.6 \\
\hline Institute graduate & & 24 & 4.8 \\
\hline College graduate \&more & & 66 & 13.2 \\
\hline Institute graduate & & 29 & 5.8 \\
\hline College graduate \&more & & 94 & 18.8 \\
\hline \multicolumn{4}{|l|}{ Place of residence } \\
\hline Urban & & 437 & 87.4 \\
\hline Rural & & 63 & 12.6 \\
\hline \multicolumn{4}{|l|}{ Economic status. } \\
\hline Adequate & & 44 & 8.8 \\
\hline Adequate to some extent & & 337 & 67.4 \\
\hline Inadequate & & 119 & 23.8 \\
\hline
\end{tabular}

Table (4.1) shows that the highest percentage (44.0\%) of study sample were at age group (15-24) years, while the lowest percentage (13.0\%) of them were at age group between (35-45) years, with the mean age and SD were $(25.63 \pm 6.167)$ years, the minimum age 16 years, the maximum age 41 years and the range age 25 years. Highest percentage (21.4\%) had not read and no write, the majority of women $(85.8 \%)$ were housewives, nearly half of the study sample (67.4\%) were mostly adequate to some extent, and the majority of them $(87.4 \%)$ Urban Place of residence.

Table (2) Pregnant Women's Reproductive Characteristics ( $\mathrm{n}=500)$.

\begin{tabular}{|c|c|c|}
\hline Reproductive characteristics & No. & $\%$ \\
\hline \multicolumn{3}{|l|}{ Gravidity (No. of pregnancy) } \\
\hline Primigravida (had one pregnancy) & 162 & 32.4 \\
\hline Multigravida (had 2-4 pregnancies) & 265 & 53.0 \\
\hline Grand multigravida (had 5-6 pregnancies) & 69 & 13.8 \\
\hline Great multigravida (had > 7 pregnancies) & 4 & 0.8 \\
\hline \multicolumn{3}{|l|}{ Parity (No. of delivery) } \\
\hline Nullipara (didn't have any type of delivery) & 170 & 34.0 \\
\hline Primipara (had one delivery) & 159 & 31.8 \\
\hline Multipara (had 2-4 deliveries) & 119 & 23.8 \\
\hline Grand multipara(had 5-6 deliveries) & 52 & 10.4 \\
\hline \multicolumn{3}{|l|}{ No .of Abortion } \\
\hline None & 318 & 63.6 \\
\hline One abortion & 125 & 25.0 \\
\hline 2 and more than & 57 & 11.4 \\
\hline \multicolumn{3}{|l|}{ No. of Stillbirth } \\
\hline None & 475 & 97.0 \\
\hline (1 to 2$)$ & 15 & 3.0 \\
\hline \multicolumn{3}{|l|}{ Consanguinity } \\
\hline Related & 172 & 34.4 \\
\hline Not related & 324 & 65.6 \\
\hline
\end{tabular}

The results shows in table (2) that more thandemonstrates the distribution of the pregnant women according to their obstetrical history. It was observed that slightly more than half of the pregnant women $(53.0 \%)$ were pregnant two to three times, while $34.0 \%$ of the pregnant women were nullipara, more than two third $(63.6 \%)$ hadn't abortion, and the majority of them $(97.0 \%)$ none stillbirth. 


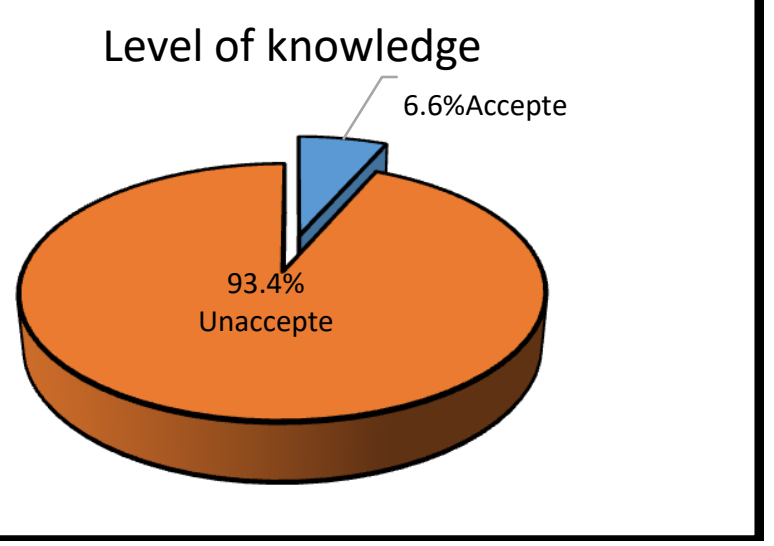

Figure (1): Level of Knowledge about Danger Signs and Symptoms for pregnant women

Table (3) Association between pregnant women's Knowledge and some study variables $(\mathrm{n}=500)$

\begin{tabular}{|c|c|c|c|c|c|c|c|c|c|}
\hline \multirow{2}{*}{\multicolumn{2}{|c|}{$\begin{array}{l}\text { Socio-Demographic } \\
\text { Variables }\end{array}$}} & \multicolumn{4}{|c|}{ Knowledge } & \multirow{2}{*}{\multicolumn{3}{|c|}{ Statistical Test }} & \multirow{3}{*}{ Sig. } \\
\hline & & \multicolumn{2}{|c|}{ Acceptable } & \multicolumn{2}{|c|}{ Unacceptable } & & & & \\
\hline & & No. & $\%$ & No. & $\%$ & $\chi^{2}$ & df & P-value & \\
\hline \multirow{3}{*}{ Age/ years } & $15-24$ & 9 & 4.1 & 211 & 95.9 & \multirow{3}{*}{4.657} & \multirow{3}{*}{2} & \multirow{3}{*}{00.097} & \multirow{3}{*}{ NS } \\
\hline & $25-34$ & 17 & 7.9 & 198 & 92.1 & & & & \\
\hline & \begin{tabular}{|r|}
$35-45$ \\
\end{tabular} & 7 & 10.8 & 58 & 89.2 & & & & \\
\hline \multirow{7}{*}{$\begin{array}{c}\text { Educational } \\
\text { level }\end{array}$} & No read and write & 0 & 0.0 & 107 & 100.0 & \multirow{7}{*}{66.83} & \multirow{7}{*}{6} & \multirow{7}{*}{0.000} & \multirow{7}{*}{$\mathrm{S}$} \\
\hline & Read \&Write & 0 & 0.0 & 64 & 100.0 & & & & \\
\hline & Primary School graduate & 9 & 8.8 & 93 & 91.2 & & & & \\
\hline & $\begin{array}{l}\text { Intermediate school } \\
\text { graduate }\end{array}$ & 0 & 0.0 & 89 & 100.0 & & & & \\
\hline & $\begin{array}{l}\text { Secondary school } \\
\text { graduates }\end{array}$ & 2 & 4.2 & 46 & 95.8 & & & & \\
\hline & Institute graduate & 5 & 20.8 & 19 & 79.2 & & & & \\
\hline & College graduate \&more & 17 & 25.8 & 49 & 74.2 & & & & \\
\hline \multirow{4}{*}{ Gravidity } & Primigravida & 13 & 8.0 & 149 & 92.0 & \multirow{4}{*}{1.399} & \multirow{4}{*}{3} & \multirow{4}{*}{0.706} & \multirow{4}{*}{ NS } \\
\hline & Multigravida & 17 & 6.4 & 248 & 93.6 & & & & \\
\hline & Grand multigravida & 3 & 4.3 & 66 & 95.7 & & & & \\
\hline & Great multigravida & 0 & 0.0 & 4 & 100.0 & & & & \\
\hline \multirow{4}{*}{ Parity } & Nullipara & 13 & 7.6 & 157 & 92.4 & \multirow{4}{*}{.0591} & \multirow{4}{*}{3} & \multirow{4}{*}{0.898} & \multirow{4}{*}{ NS } \\
\hline & Primipara & 9 & 5.7 & 150 & 94.3 & & & & \\
\hline & Multipara & 8 & 6.7 & 111 & 93.3 & & & & \\
\hline & Grand multipara & 3 & 5.8 & 49 & 94.2 & & & & \\
\hline \multirow{3}{*}{ No .of Abortion } & None & 22 & 6.9 & 296 & 93.1 & \multirow{3}{*}{1.145} & \multirow{3}{*}{2} & \multirow{3}{*}{0.564} & \multirow{3}{*}{ NS } \\
\hline & One abortion & 6 & 4.8 & 119 & 95.2 & & & & \\
\hline & Two and more than & 5 & 8.8 & 52 & 91.2 & & & & \\
\hline & None & 32 & 6.8 & 437 & 93.2 & & & & \\
\hline No. of Stillbirth & 1 & 1 & 7.1 & 13 & 92.9 & 1.246 & 2 & 0.536 & NS \\
\hline & 2 more & 0 & 0.0 & 17 & 100.0 & & & & \\
\hline
\end{tabular}

( df) degree of freedom, (Sig) significant Probability value (P < 0.05), (NS) Non Significant.

Table (4) results shows that there was no statistical significant differences between pregnant women's knowledge and study variables.

\section{Discussion}

Essentially, all women in developing countries are at risk of obstetric complications. These complications are virtually inconceivable to anticipate and hard to forestall .Medical and nursing management for women with obstetric complications begins with the recognition of danger signs. Because lack of knowledge about danger signs of obstetric complications often delays decision-making for health care service seeking, resulting in tragic consequences, where women die at home or in their way to the health facility.

This study therefore aimed to assess the current status of knowledge of pregnant women about danger signs and symptoms during pregnancy. Concerning the overall knowledge total score level regarding danger signs and symptoms during pregnancy, the findings of the present study revealed that about more than ninety percent of the study sample was the level of knowledge is unacceptable (low) about danger signs and symptoms during pregnancy. This finding is in agreement with (Abrahim et al., 2017) inEgypt, (Gebrehiwot et al., 2014) in Mekelle, Ethiopia and (Kavitha, Prasath et al, 2014) inNigeria. They reported that women generally had poor 
knowledge of danger signs and symptoms during pregnancy. ${ }^{(5,6,7)}$ Also, this finding was concur with a study conducted by(Solomon et al., 2014) in Central Ethiopia, (Mwilike et al., 2013) in Tanzania , (Okura et al., 2012) in Jordan, (Rashad et al., 2010) in Egypt, who reported low levels of knowledge about danger signs and symptoms ${ }^{(8,9,3,10)}$ Regarding association between pregnant women's knowledge women's and study variables this study shows that there are a statistical significant differences between pregnant women's knowledge and socio demographic variables, while no statistical significance differences between pregnant women's knowledge and reproductive characteristics, this finding agree with that reported in Jordan by (Okura et al, 2012), in Egypt by (Rashad, 2010), in Egypt conducted by (Abrahim et al, 2017), in North Ethiopia by (Nurgi, et. al., 2014), in Debra Town, Ethiopia by (Solomon et al, 2014), ,in Ethiopia by (Ndudi et al 2015), in Debar Towne in Ethiopia by (Mengesha et al , 2012 ) and in Tanzania by (Mwilke et al, 2007). ${ }^{(3,5,8,9,10,, 12,13,14,15)}$

\section{Conclusion}

The study conducted that majority of study sample at low knowledge about danger signs andsymptoms. A significant correlation was found between pregnant women's level of education, occupation and their knowledge about danger signs and symptoms during pregnancy.

\section{Recommendations}

Raising women's awareness along with expansion of antenatal care services which might be important strategies to increase protect pregnant women from obstetric complications, in addition, Launching effective mass media campaign to create awareness among women, their husbands and families about importance of danger signs and symptoms ,this is like electronic media, pamphlets, posters, magazines and books that help women, families and communities increase their awareness and knowledge concerning obstetric danger signs.

\section{References}

[1] Killewo, J., Anwar, I., Bashir, I., Yunus, M., \& Chakraborty, J. Perceived delay in healthcare-seeking for episodes of serious illness and its implications for safe motherhood interventions in rural Bangladesh. 2006. Available from:- Journal Health Popul Nutrition. Retrieved 17/10/2016

[2] Hogan J, Maguire P, Farah N, Kennelly M, Stuart B, Turner M. Body Mass Index and Blood Pressure Measurement during Pregnancy. Hypertension in Pregnancy 2010. Available from: The lancet journal Retrieved 6/12/2016.

[3] Okour A, Alkhateeb M, Amarin Z . Awareness of Danger Signs \& Symptoms of Pregnancy Complication Among Women in Jordan ,2012. Available from: International Journal Gynecologic Obstetric . Retrieved 2/9/2016

[4] Chowdhury, R. I., Islam, M. A., Gulshan, J., \& Chakraborty, N. Delivery complications and healthcare-seeking behaviour: the Bangladesh Demographic Health Survey, 2007,254-64, Available from:-Health Soc Care Community, doi: 10.1111/j.13652524.2006.0068. Retrieved 8/11/2016.

[5] Ebrahim A, Hassan M, El-SalamG, Knowledge and practices of pregnant women regarding danger signs of obstetric complications in Egypt. 2017. Availablefrom:IOSR Journal of Nursing and Health Science . Retrieved 2/3/2017.

[6] Gebrehiwot H., Bahta S., and Haile N. Awareness of danger signs of pregnancy and its associated factors in Mekelle public hospitals, 2014. Department of Midwifery, College of Health Sciences, Mekelle University, Ethiopia. Available from:American Journal of Delivery.www.ajadd.co.uk.Retrieved 13/10/2016.

[7] Kavitha P, Prasath R, and Krishnaraj P. A study to assess the effectiveness of structured teaching program on warning signs during pregnancy in terms of knowledge, practice, and attitude among antenatal mothers, 2012. Available from:- Journal of Science Vol 2 / Issue 1. Retrieved 12/1/ 2017

[8] Solomon A, Amanta N, Chirkose E. Knowledge about danger signs of pregnancy and associated factors among pregnant women in Debra Birhan town, public health institutions, central Ethiopia. Department of Midwifery, College of Medicine and Health Sciences, University of Gondar. 2015. Available from:Published http://www.sciencepublishinggroup.com/j/sjph) ,Retrieval $3 / 9 / 2016$

[9] 9.Mwilike B. knowledge of Danger Signs during Pregnancy and Subsequent Health Seeking Actions among Women in Kinondoni Municipality, Tanzania. 2013. Available from:http://imstpt.ap.nic.in/jcsr.pdf. Retrieved 4/9/2016.

[10] Rashad W, Essa R. Women's awareness of danger signs of obstetric complications in Egypt . University of Alexandria 2010. Available from: Journal of American Science. Retrieved 2/11/2016

[11] Hailu M, Gebremariam A, Alemseged F. Knowledge about obstetric danger signs in Aleta Wondo district, Sidama Zone, South Ethiopia.February 20, 2007. Available from: http:// www. ncbi. nlm.nih. gov Retrieved 6/8/2016.

[12] Sufiyan MB, Adam N, Umar AA, Ibrahim JM, Bashir SS, Birukila G. Knowledge, attitude and perception of pregnancy danger signs among women of childbearing age in samaru community Northwestern Nigeria 1 Archives of Medicine and Surgery 2012,vol.1 1:24-9. Available from: http://www.archms.org/text.asp?2016/1/2/24/204801 . Retrieved 11/4/2017

[13] Mengesha E. ,level of awareness on danger signs of pregnancy and associated factors among antenatal care attendant women in Debark Town, North Gondar, Ethiopia 2012. Available from: Translational Latina medicine and biotechnology ISSN .Retrieved $4 / 12 / 2016$

[14] Ndudi E., Sunday B. knowledge of key danger signs of pregnancy among clients of maternal health service in urban and rural primary health centres of southeast Nigeria. 2015. Available from: Journal of Community Medicine \& Health Education Retrieved $4 / 12 / 2016$

[15] Nurgi S. Assessment of knowledge, attitude and practices of Obstetric Danger Signs among Mothers in Debre Birhan Debre Berhan City Administration, North Shoa zone, Amhara region, Ethiopia. Msc Thesis. College of Health Science, Department of Nursing and Midwifery, Addis Ababa University, 2014. Available from: Journal of American Science. Retrieved 7/1/2017

Anaam Abdulkareem Abas. "Knowledge about Danger Signs and Symptoms of Pregnant Women Attending Antenatal Care Centers in Baghdad City." IOSR Journal of Nursing and Health Science (IOSR-JNHS) 6.4 (2017): 37-40. 